\title{
A construção de diferentes imaginários pelo sonoro de Maurice Ravel e as imagens de Tom Scott: o caso particular da Suite Ma mère l'Oye
}

\author{
Helena Maria da Silva Santana \\ Universidade de Aveiro, Portugal \\ Maria do Rosário da Silva Santana \\ Instituto Politécnico da Guarda, Portugal
}

\begin{abstract}
Originally written as a five-movement piano duet, Ma mère l'Oye, composed by Maurice Ravel in 1910, it's a musical Suite. Dedicated to the Godebski children, the piece was transcribed for solo piano by Jacques Charlot the same year as it was published (1910). Both piano versions bear the subtitle "cinq pièces enfantines" (five children's pieces). Sleeping Beauty and Little Tom Thumb are based on the tales of Charles Perrault, while Little Ugly Girl and Empress of the Pagodas is inspired by a tale (The Green Serpent) by Madame d'Aulnoy. In 1911, Ravel orchestrated the work. This form is the most frequently heard today. Later the same year, 1911, he also expanded it into a ballet, separating the five initial pieces with four new interludes and adding two movements at the start, Prélude and first framework- Danse du rouet et scène. More recently, we have the animated proposal by Tom Scott.

In our proposal, it is our intention to understand how the imaginary soundscape is up to date by the animation proposal by Tom Scott in order to elucidate his contents, but we also intent two understand how the musical work transforme the discourse of Tom Scott.

Additionally, and because the musical piece has four versions, we want to analyze the differences between the original work for piano, the orchestral proposal, the little ballet and the last one - the animation by Tom Scott.
\end{abstract}

Keywords: Maurice Ravel, Tom Scott, Musical Suite, Charles Perrault, Madame d'Aulnoy.

\section{Introdução}

A variabilidade de expressões e de conteúdos proposta ao longo das cinco pequenas curtas-metragens que compõem a proposta de "Ma Mère l'Oye" com música de Maurice Ravel (1875-1937), interpretação dos Scott Brothers Duo ${ }^{1}$ e animação da autoria de Tom Scott, bem como a pluralidade de formas e dimensões criativas das suas componentes, torna a reflexão sobre a obra, a sua coerência formal, expressiva e artística, bem como o mundo em que se insere - o universo e o imaginário dos contos de fadas infantis e a animação fílmica-, uma proposta importante para ser examinada. Ao refletir sobre uma obra desta natureza, uma obra realizada sobre uma temática que, de forma geral, aborda uma apresentação e discussão de diversas moralidades, prevemos uma reflexão sobre a maneira como os autores inferem sobre o facto. Através da ilustração de cino contos de fadas, mas, que, de forma individual, se especifica em muitas particularidades, pretendemos concluir sobre um problema fundamental para a criação artística contemporânea: o problema da determinação da forma da obra em paralelo com a sua ilustração sonora, e, simultaneamente, pensar na transformação do sonoro pela imagética versada. Surge-nos evidente que a estrutura formal da obra que se constrói no dizer das partes, se diz, igualmente, no dizer do todo. Este facto leva-nos a refletir sobre o processo de demarcação de cada uma das curtas-metragens, em relação ao todo, e de cada uma em relação ao tema, bem como à forma como a criação das partes, concorre para a determinação do todo. Esta prática se revela num fazer próprio à determinação da estrutura formal geral da obra proposta pelo compositor - a forma Suíte -, e, como referido, na estrutura de cada uma das suas componentes individualmente.

Do ponto de vista criativo, de finais do século XIX até início do século XX, o contraste entre a produção musical francesa, consentânea com a nacionalidade do compositor, e a de outros países da Europa, é um facto. Enquanto em França se mostra um desenvolvimento cultural marcante, fruto de inúmeras influências, nomeadamente extraeuropeias, na Alemanha, por exemplo, vimos um decréscimo, não de importância, mas da variedade de conteúdos expressos som e arte, bem como nas influências aí ditas. Sabemos da importância da França no que concerne a criação artística ao nível da pintura e das artes plásticas em geral, bem como da música, da arquitetura ou da literatura. Acresce uma permanência de vários autores no seu território, mormente em Paris, autores de outras nacionalidades, sejam pintores, poetas, escritores, músicos intérpretes ou compositores, revigorando a produção musical e artística deste período ${ }^{2}$. A esta influência e variedade não se encontra alheio Ravel.

Em outro, e no que concerne a arte de uma forma geral, e mais precisamente a arte decorativa, sabemos que em 1900, esta triunfa aquando da Exposição Universal de Paris, sendo que aquilo que se estabeleceu enquanto arquitetura, escultura, pintura e música, e aquilo que se elaborou após este magnífico evento, denotam a influência de tudo o que foi vivido e usufruído nesta data ${ }^{3}$. Paralelamente, a criação visando os espaços públicos ao ar livre, fora das salas de concerto tradicionais, também se mostra presente, assim como a influência de outras culturas, mormente as culturas extraeuropeias ${ }^{4}$. Este facto promove a propagação de novas maneiras de olhar os artefactos, os instrumentos, os ensembles e as sonoridades que possibilitam, delineando-se ainda novas formas 
de emprego das estruturas formais de uma obra, bem como dos meios orquestrais disponíveis. Neste sentido, somos a referir o uso da grande orquestra, assim como de todos os instrumentos de percussão de influência extraeuropeia, e não só, um repositório de possibilidades timbricas, sonoras e instrumentais que deslumbram os ouvidos de qualquer músico compositor ou músico intérprete, mas também de qualquer ouvinte. A criação musical englobando e/ou colaborando com outras áreas da criação artística, nomeadamente a literatura, a pintura, o cinema, a arquitetura e a dança, proliferam. Logo, surgem numerosas propostas artísticas onde a literatura e a música se complementam, alcançadas numa realidade onde o texto, direta ou indiretamente, se versa música, e onde a música e o texto, se dizem imagem. No caso aqui exposto, prevemos o versar de um ideário infantil, nomeadamente o dos Contos de Fadas Infantil da autoria de Charles Perrault (1628-1703), na obra Ma Mère l'Oye (1910) de Maurice Ravel, facto que possibilitou a sua animação por parte de Tom Scott (Scott \& Scott 2011).

\section{Maurice Ravel}

A vida e obra de Maurice Ravel reveste-se de uma enorme polémica. Esta circunstância, deve-se ao facto de o compositor manifestar, a nível sonoro e musical, fortes semelhanças, do ponto de vista técnico, estilístico e estético, com o seu compatriota Claude Debussy (1862-1918). Contudo, uma análise mais atenta da sua obra revela as dissemelhanças, bem como a sua forte e proficiente personalidade criativa. Nascido em 1875 em Ciboure, próximo de Espanha, o compositor tem, por parte de sua mãe, ascendência espanhola. Deste facto, decorre uma influência da música e cultura deste país, circunstância que se concretizará em algumas das suas obras mais marcantes ${ }^{5}$. Bastante dotado do ponto de vista musical, estuda com Gabriel Fauré (1845-1924), publicando diversas obras mesmo antes de terminar os seus estudos musicais. Em 1905, no limite da idade, concorre ao Concurso de Roma, não tendo sido admitido. Este facto gerou enorme controvérsia, sendo um fator de discussão pública e privada, que se focou tanto na sua vida, como na sua obra (Lamarque 1992) ${ }^{6}$. O seu primeiro período criativo, o mais fecundo e satisfatório para o compositor, visa duas décadas da sua produção artística. Iniciando sempre com uma obra para piano, terminam com uma obra para grande orquestra, sob a forma de ballet ${ }^{7}$. A primeira das duas décadas inicia com a obra Menuet antique (1895) e termina com a obra Daphnis (1910); a segunda inaugura com a obra Ma Mère l'Oye terminando com a grande obra La Valse (1919) (Robert 1963) ${ }^{8}$. Enquanto compositor, Maurice Ravel submete-se às regras de composição mais tradicionais. No entanto, tenta levar a sua criação musical um pouco mais além ${ }^{9}$. A cada obra intenta resolver um novo problema de criação e uma nova questão de composição, sendo que, a nível rítmico, a sua produção adquire um dinamismo que lhe infunde uma atividade rítmica, métrica e temporal definitivamente inovadoras ${ }^{10}$. Pela repetição continuada de uma fórmula pré construída, a sua música torna-se encantatória ${ }^{11}$. Em outro, revela-se um excelente orquestrador utilizando os timbres com um elevado sentido estético e musical, mas também poético, endereçando-nos sempre um elevado refinamento musical.

Quoi de plus séduisant que l'orchestre de Ravel ? Et pourtant, bon nombre de ses œuvres ont d'abord été conçues pour le piano. A la suite de Liszt et de Schumann, qu'il admirait, Ravel transfigurait le clavier avec une diversité étonnante. Dans la lignée des compositeurs russes, de Chabrier aussi, il va faire chanter les instruments de l'orchestre avec la même variété, mettant en relief une notion capitale que la musique contemporaine devait exploiter bien davantage (mais qui était présente chez Monteverdi et Rameau, précurseurs de génie), - celle de timbre instrumental. Avec un orchestre généralement plus modeste que celui des postromantiques, et grâce à un langage harmonique qui, tout en restant extrêmement personnel, se coule encore dans le moule du classicisme, Orchestrer, pour Ravel, c'est révéler l'idée musicale sous son angle le plus lumineux, sans excès, sans surcharge ; c'est diversifier les couleurs et faire ressortir l'individualité de chacune ; d'où l'extrême attention portée aux divers groupes de percussion, les nuances subtiles des bois, les glissandos, les trémolos, les cordes divisées (...). C'est en cela que Ravel est véritablement moderne, non seulement dans ses propres œuvres mais dans celles d'autres compositeurs qu'il orchestra avec génie. (Tranchefort 1985, 87).

Maurice Ravel demonstra, melhor que ninguém, que aquilo que não é necessário, é inútil, rejeitando-o (Robert 1963).

\section{0 sonoro de Maurice Ravel revisitado no discurso e nas imagens de Tom Scott - a Suíte Ma Mère l'Oye}

Ma Mère l'Oye (Mãe Gansa, 1910), da autoria de Maurice Ravel, foi originalmente escrita para o piano. Composta para presentear os filhos do seu grande amigo Cipa Godebsky, Mimie Godebsky e Jean Godebsky, a obra foi publicada em $1910^{12}$. Inspirando-se num género específico de literatura infantil - os Contos de Fada, nomeadamente os Contos de Fada Ma Mère l'Oye da autoria de Charles Perrault (Perrault 1994), sabemos que, ao imaginário literário base da obra da autoria deste, acrescem alguns contos da autoria da Condessa d'Aulnoy (1651-1705). O conto de fadas revela-se um género literário que permite 0 desenvolvimento do imaginário infantil $e$, sobretudo, da leitura e da narração. Através da narração de uma história que, por ser infantil e pertencer a um género em particular, possui contornos e princípios próprios, vemos a possibilidade de um confronto com diversas realidades, com diversos problemas e medos, traumas e aspirações, que, por via de uma resolução que se quer positiva, a criança aprende a lidar com esses mesmos medos, traumas, incertezas e aspirações. 
De forma a não estarmos à mercê dos caprichos da vida, é preciso desenvolvermos os nossos recursos interiores, para que as nossas emoções, imaginação e intelecto se apoiem e se enriqueçam mutuamente. Os nossos sentimentos positivos dão-nos força para desenvolver a nossa racionalidade, só a esperança no futuro nos pode sustentar nas adversidades que inevitavelmente encontramos (Bettelheim 1998, 10).

A aquisição de diversas habilidades, sejam cognitivas, emotivas ou vivenciais, passa pelo ato da leitura e construção de conhecimento a partir desta e dos ideários e imaginários descritos. Contudo, a aquisição dessas habilidades, principalmente a da leitura, perde valor quando o que se aprende não acrescenta nada de novo ao que já detemos, e mais importante ainda, não promove o nosso desenvolvimento intelectual, emotivo e social. Nesse sentido, a leitura de contos e narrativas infantis que incluam conteúdo moral e cívico revela-se importante para o desenvolvimento psicossocial da criança, nomeadamente a nível psicológico e relacional. Simultaneamente, para que uma história prenda a atenção da criança, torna-se necessário que ela a distraia, mas que lhe desperte igualmente a atenção e a curiosidade. Para que a sua existência saia enriquecida, é necessário que ela estimule a sua imaginação ajudando-a a desenvolver o seu intelecto e a esclarecer, de forma positiva, as suas emoções. Neste sentido, a narrativa deve

\begin{abstract}
estar sintonizada com as suas angústias e as suas aspirações; tem de reconhecer plenamente as suas dificuldades e, ao mesmo tempo, sugerir soluções para os problemas que a perturbam. Em suma, precisa de estar simultaneamente relacionada com todos os aspetos da sua personalidade e isto sem nunca amesquinhar, mas, pelo contrário, dando todo o crédito à seriedade das suas exigências e dando-lhe conjuntamente confiança em si própria e no futuro. [...] Neste e noutros aspetos [...] nada é mais satisfatório, quer para a criança quer para o adulto, do que o popular conto de fadas (Bettelheim 1998, 11).
\end{abstract}

Fruto de um interesse do compositor por este género literário, e por esta obra - Ma Mère l'Oye -, em particular, o compositor dá seguimento à composição de um conjunto de cinco pequenas peças para piano a quatro mãos, peças de caráter infantil, mas que denotam uma intenção formativa e moralizante marcada. Esta intenção encontramo-la nas numerosas citações que faz do texto de Charles Perrault no cabeçalho de cada uma das suas pequenas e ilustrativas peças ${ }^{13}$. Ma Mère l'Oye revela-nos o imaginário do autor transposto para o sonoro através da mestria do compositor. A obra é tão marcante que, em 1910, Jacques Charlot a transcreve para piano solo. Em 1911, a peça foi orquestrada pelo próprio compositor, que adicionou novas partes, dando seguimento à criação de um pequeno ballet ${ }^{14}$.

No que concerne a coletânea de Contos de Fada proposta por Charles Perrault (1628-1703), e o seu autor, sabemos que Perrault foi um escritor e poeta francês do século XVII, que estabeleceu as bases para este género literário, que, à época, surge inovador ${ }^{15}$. As suas histórias mais conhecidas, Le Petit Chaperon rouge (o Capuxinho Vermelho), La Belle au bois dormant (A Bela Adormecida), Le Maître chat ou Le Chat botté (O Gato de Botas), Cendrillon ou La petite pantoufle de verre (Cinderella), La Barbe bleue (Barba Azul) e Le Petit Poucet (O Pequeno Polegar), encontram-se, todas elas, na coletânea intitulada Contes Ma Mère l'Oye (Perrault 1994), obra sobre a qual Ravel se debruçou. A maioria das suas histórias, dada a sua pertinência, ainda hoje são editadas, traduzidas e distribuídas em diversos países do mundo, sendo frequentemente adaptadas para várias formas de expressão artística, como o teatro, o cinema e a televisão ${ }^{16}$. A pertinência das suas histórias estará certamente ligada à necessidade, que atravessa todas as épocas,

[...] de uma educação moral em que com subtileza apenas se lhe transmitam [à criança e a quem lê a narrativa], as vantagens de um comportamento moral, não através de conceitos éticos abstractos mas através do que parece palpavelmente acertado e portanto com sentido para a criança (Bettelheim 1998, 12).

Publicado em 1697 sob o título Histoires ou contes du temps passé (Histórias ou contos do tempo passado), este conjunto de contos engloba um conjunto de nove contos com moralidades, a saber: À Mademoiselle; La Belle au Bois dormant; Le Petit Chaperon rouge; La Barbe Blue; Le Maître Chat ou le Chat botté; Les Fées; Cendrillon ou la Pette Pantoufle de verre; Riquet à la houppe e Le Petit Poucet. Acrescem cinco contos em verso, a saber, À Mademoiselle; Griselidis; À Monsieur; Peau-d'Âne; Les Souhaits ridicules, precedidos de um Préface. Embora tenha ficado conhecido pelo seu subtítulo: Les Contes de Ma Mêre l'Oye (Contos da Mãe Gansa), a obra engloba os contos com moralidade seja em prosa (primeiros nove), ou em verso (últimos cinco). $O$ conteúdo moral que acompanha as histórias surge em forma de verso no seu final, encerrando cada história (Perrault 1994). No que concerne a obra de Ravel, e apesar da designação de Ma Mère l'Oye (Mãe Gansa), a obra foi inspirada em diversos contos de fada de uma forma geral, e não somente, na recolha homónima de Charles Perrault (1994).

Ao longo dos séculos (senão milénios), contados e recontados, os contos de fadas foram-se refinando cada vez mais e acabaram por transmitir, ao mesmo tempo, significações - manifestas e latentes dirigindo-se simultaneamente a todos os níveis da personalidade humana e comunicando de uma forma que chega ao espírito inculto da criança, assim como ao do adulto sofisticado (Bettelheim 1998, 12).

A palavra conto deriva do latim de "computu(m), contu(m), cálculo, conta ou commentu(m), invenção, ficção. Segundo ele, o conto é 
de génese desconhecida e remonta aos primórdios da própria arte literária. Na Idade Média, já era mencionado como "enumeração de fatos", "relato", "narrativa", embora não guardasse nenhum vínculo com a literatura. ${ }^{17}$ (Baião 2005, 47).

Por outro lado, a palavra fada, naturalmente associada a um contexto fantasioso e sobrenatural, provém do verbo fatare, encantar, e do substantivo fatum, fado ou destino, ambos oriundos do latim. Às fadas, seres dotados de poderes mágicos, cabia a tarefa de zelar pela sorte e pelo destino dos humanos orientando-os desde o seu nascimento. As fadas, e o imaginário a elas adstrito, estão presentes em quase todas as culturas, povoando, por isso, o imaginário de todos. (Baião 2005, 50). Ao reescrever esses contos, inicialmente apontados como

vulgares e toscos, Perrault substitui o vocabulário camponês das velhas fiandeiras por um outro mais refinado e conveniente aos filhos dos distintos aristocratas franceses. Sua intenção, revelada por, pelo menos um verso ao final de cada conto, explicita-se através de um discurso focado em valores morais com a pretensão de estabelecer princípios de boa conduta e de ressaltar virtudes indispensáveis à formação do indivíduo. (Baião 2005, 53).

Neste sentido, e no de salientar o interesse do compositor por universos imagéticos infantis, Steven Ledbetter escreve:

Ravel pôde, apesar de ser um adulto, entrar no mundo da infância como poucos compositores tinham conseguido até então. Pode ser que essa afinidade [com o mundo infantil] viesse de uma paixão comum compartilhada por brinquedos especialmente os mecânicos (...). Sua simpatia pelo modo de pensar da criança é revelada em suas respostas sobre uma série de ilustrações de contos de fadas franceses, que ele usou como ideia para a composição de uma singela suíte, para piano a quatro mãos, e que ele nomeou, Ma Mère L'Oye." (Ledbetter as cited in Baião 2005, 55).

No que concerne a obra de Ravel, a sua estrutura original, compõe-se de cinco pequenas peças (Ravel 1910 $)^{18}$. São elas: I. Pavane de la Belle au bois dormant (Pavana da Bela Adormecida); II. Petit Poucet (O Pequeno Polegar); III. Laideronnette, Impératrice des pagodes Laideronnete, (Imperatriz dos Pagodes (inspirada no conto "A Serpente Verde" da autoria da Condessa d'Aulnoy); IV. Les entretiens de la Belle et de la Bête (Os Colóquios da Bela e do Monstro da autoria de Madame Leprince de Beaumont); V. Le jardin féerique (O Jardim Feérico) ${ }^{19}$.

A proposta fílmica aqui em análise, da autoria de Tom Scott, incide sobre os cinco andamentos da estrutura original da obra. Por serem pequenas peças infantis, Ravel propõe um sonoro de grande poder descritivo, pictórico e encantatório. Reflete as influências mais marcantes da época, nomeadamente a de diversas culturas extraeuropeias, facto não alheio a Scott. O poder encantatório destas pequenas peças, advém não só do imaginário proposto em cada designação de obra, como em algumas citações de Perrault incluídas no início de cada peça (Ravel 1910, 4, 5, 10, 11, 20, 21), da economia de meios, bem como da natureza dos motivos musicais. A repetição de melodias extremamente simples, torna-se encantatório, e, ao se revelarem magistralmente construídas, harmonizadas e concordantes com as possibilidades do instrumento para a qual foram escritas, são o indício da mestria e da capacidade criativa do seu autor. Tom Scott, aproveitando o poder descritivo e pictórico das pequenas ilustrações musicais de Maurice Ravel, propõe também ele, um imaginário visual que, de descritivo, pictórico e encantatório, se revela também ele de uma beleza e elegância sem igual (Scott \& Scott 2011).

\subsection{Pavane de la Belle au bois dormant (Pavana da Bela Adormecida)}

É característico dos contos de fadas expôr um dilema existencial de forma direta e concisa. Isto permite que a criança enfrente logo o problema na sua forma mais essencial, ao passo que um enredo mais complexo seria para ela mais confuso e difícil de captar, discernir e apreender. Assim, e em praticamente todos os contos de fadas, encontramos referencia ao bem e ao mal, à vida e à morte, à desilusão e à esperança, à angústia e ao medo, elementos que se mostram omnipresentes, como o estão na vida de todos, e de cada um de nós. Nesta dualidade, nesta luta constante, a criança, de forma lúdica, mas igualmente informada e capaz, tem a possibilidade de se confrontar com um problema moral que exige uma luta para se resolver. Acresce o conteúdo moral e a forma como finalizam, sempre positiva para que se revele esperança. De forma a permitir a formação psicológica e emocional da criança, e muitas das vezes do adulto que narra a história, o conto de fadas traz uma mensagem. Essa mensagem, surgindo por múltiplas e diversas formas é a de que:

a luta contra graves dificuldades na vida é inevitável, faz parte intrínseca da existência humana - mas que se o homem se não furtar a ela, e com coragem e determinação enfrentar as dificuldades, muitas vezes inesperadas e injustas, acabará por dominar todos os obstáculos e sair vitorioso (Bettelheim 1998, 15).

Assim se constrói a narrativa ao longo de toda esta coletânea de contos, e, em A Bela Adormecida, em particular.

Musicalmente, a pequena peça, com cerca de 1' 47", reflete um espaço onírico, aquele de $A$ Bela Adormecida. De pequenas dimensões, e com um carácter infantil:

The first movement, Pavane of the Sleeping Beauty (Pavane de la Belle au bois dormant) is only 20 bars long but concentrates a great deal of grace and beauty into that small space, suggesting the quiet atmosphere of the beauty's perpetual slumber (Scott \& Scott 2011). 
No que concerne a peça musical, e segundo afirmações do próprio Ravel: "the idea of evoking in these pieces the poetry of childhood naturally led me to simplify my style and to refine my means of expression" (Scott \& Scott 2011). Neste sentido, antecipamos que a simplificação da obra, do seu conteúdo, forma e estilo, a tornam tão eficiente e eficaz na tradução de um conteúdo expressivo e musical, como o original conto de fadas. A forma musical para descrever esse espaço, a Pavana, é aquela de uma antiga dança espanhola, nobre e lenta, em ritmo binário ou quaternário (Ravel 1910, 2-3).

A proposta de Ravel, com a extensão de 20 compassos, surge num andamento lento (semínima = 58 M.M.), compasso quaternário, denotando uma quadratura extrema (as linhas melódicas surgem de 4 em 4 compassos; 4 x 5 compassos).

De influência espanhola, a dança já existia desde os séculos XVI e XVII, ou seja, desde a época de Charles Perrault. O sono de A Bela Adormecida aparece embalado pela doce e suave melodia. De caráter ondulatório e modal, coopera para a definição de um universo mágico e distante, propício ao adormecer da Bela e de todos os que se propõem a obra fruir. A proposta de Tom Scott, mágica também, conduz o espectador por uma luz encantatória (Scott \& Scott 2011). Ondulando por um caminho tortuoso, como sinuosa se mostra a melodia, leva-nos a Bela Adormecida. Qual príncipe encantado, ela vai junto de Bela e a toca. O universo mais sombrio da noite transfigura-se na luminosidade e conforto do espaço e da luz interior do palácio, o aconchego do fogo e da lareira, a presença dos elementos consentâneos com a vivência da sua paz, do seu equilíbrio e do seu amor.

A proposta visual de Scott vai-se definindo nos elementos da estrutura musical. A noite e as estrelas são representadas pelos pontos de luz e pelo mocho que se encontra sobre a árvore (0'25'). A melodia ondulante e encantatória no registo agudo do piano segue o desenrolar da caminhada da luz que surge e intenta visitar Bela (0'29"). Ao minuto 0'50" transforma-se o colorido da proposta, como se transforma o lugar da ação e os elementos musicais nele incorporados. Ao chegar à janela de Bela, e ao se modificar a ação, Ravel propõe uma cadência intermédia, desenhada logo após uma nova melodia e secção na sua obra musical. Ao retomar a melodia, retoma também o tema (1'29'), sendo que a peça possui uma forma em estrutura que se revela tripartida (Scott \& Scott 2011).

\subsection{Petit Poucet (O Pequeno Polegar)}

O Pequeno Polegar pensava encontrar o caminho de volta a casa pelo facto de ir deixando, ao longo deste, pequenos pedaços de pão. A animação ilustra essa ação, mostrando um caminho por onde a criança caminha e vai deixando cair pequenos pedaços de pão para poder, através deles e do rasto que desenha, encontrar o caminho de volta para casa. Ela não vê, com certeza, o pássaro que desde o início da ilustração a cerca do alto pousado no cimo de uma árvore e que lhe vai comer todas os pedaços de pão comprometendo-lhe, assim, o retorno a casa (Scott \& Scott 2011).

Sabemos que os contos de fadas levam muito a sério a questão dos medos e das angústias existenciais. O medo de não conseguir retornar a casa, o medo de não se conseguir alimentar, o medo de não ser querido e amado, transcorre todos estes contos. No caso particular de o Pequeno Polegar, o rapaz vivencia uma luta, uma angústia e um dilema. O primeiro passa por deitar ao chão o pão que o pode alimentar; o segundo, o de não conseguir retornar a casa e ao conforto dos familiares amados. O Conto de fadas aborda estas questões de forma direta usando sempre personagens que não mostram qualquer ambivalência, ou seja, ou são boas ou são más, nunca são boas e más simultaneamente, como acontece com todos nós (Bettelheim 1998).

Musicalmente, e em Petit Poucet, Ravel propõe novamente uma pequena peça, com cerca de 3', onde a presença de uma melodia de caráter repetitivo e ondulatório se demarca (Ravel 1910, 4-8). A partitura contém esta informação, esta ambivalência e angústia, uma informação contida numa citação do próprio Perrault:

il croyait trouver aisémente son chemim par le moyen de son pain qu'il avait semé partout où il avait passé; mais il fut bien surprise lors qu'il n'en put retrouver une seule miette: les oiseaux étaient venus qui araient tout mangé" (Perrault in Ravel 1910, 4).

No sentido de elucidar todo este conteúdo imagético e expressivo,

Ravel creates a sense of bewilderment and unease with an accompaniment of constantly shifting meter and a plaintive melody which is searching for a way home. The 'birds' are clearly audible at the top of the piano as they chirp and twitter whilst eating the crumbs (Scott \& Scott 2011).

Em outro, o discurso musical, num movimento circular ascendente, pretende atingir um clímax de tensão física e psicológica. Enquanto género literário, o conto de fadas surge sempre orientado para o futuro, guiando a criança (Bettelheim 1998). É neste sentido evolutivo, como evolutiva é toda a obra musical aqui proposta, que se faz e diz o conto e a vida.

Assim, Ravel propõe uma obra, uma pequena peça musical, em andamento Très modere (semínima $=66$ M.M.), sendo que ao compasso previsto no seu início, Ravel contrapõe sempre compassos de uma outra natureza. Do facto, propomos o exemplo do início da peça, onde o autor sequencia um compasso binário, ternário, quaternário e quinário, o que introduz uma irregularidade e impermanência que visa alertar para um perigo, uma instabilidade. De notar ainda que, e no nosso entender, a repetição circular ascendente da melodia e o cromatismo que, entretanto, se nota, nos leva ao clímax da obra, dando-se um movimento descendente logo em seguida, de natureza também ele cromático (Ravel 1910, 4). Se a instabilidade e a impermanência se revelam no dizer musical, 
também sucedem na proposta de Tom Scott (Scott \& Scott 2011), conduzindo ao ponto em que surge uma borboleta que intenta pousar na mão de Pequeno Polegar, mas se assusta com o bocado de pão que cai do céu (1'26"). Cai o pão e muda o sentido dessa mesma melodia que, a partir de agora, se faz descendente. $O$ seu carácter também se torna mais sombrio. Um pouco depois surgem diversos animais na floresta: um grilo (1'57'), prontamente ilustrado musicalmente por uma apojeitura que se repete; o cuco (2'14") revelado pela sua interlocução característica. E a obra se vai dizendo num contínuo repetir do mesmo material em modos distintos (maior e menor). No final da pequena peça (2'45"), retoma o tema inicial, como uma coda, finalizando o seu discurso, bem como o das imagens, agora numa tonalidade sombria, lembrando a noite que se avizinha.

\subsection{Laideronnette, Impératrice des pagodes (Laideronnete, Imperatriz dos Pagodes)}

A terceira das peças, intitulada Laideronnette, Impératrice des Pagodes, também inicia com uma citação, neste caso de Mme D'Aulnouy:

\begin{abstract}
Elle se déshabilla et se mit dans le bain. Aussitôt pagodes et pagodines se mirent à chanter et à jouer des instruments : tels avaient des théorbes faits d'une coquille de noix; tels avaient des violes faites d'une coquille d'amande; ca ril fallait bien proportionner les instruments à leur taille. (Mme d'Aulnoy : Serpent Vert)" (Ravel 1910, 10)
\end{abstract}

No que concerne o imaginário do conto proposto, apuramos que a proposta de Tom Scott contém todos estes elementos, bem como o conteúdo moralista e informativo do conto. No seu dizer:

A pagoda is a Chinese figurine with a grotesque face and a movable head (a popular decorating accessory in 18th-century France). In the story, Laideronnette is a Chinese princess who has been cursed with horrible ugliness and wanders for years with her only companion, an equally ugly green serpent. They are shipwrecked in the island of the pagodas and the little porcelain people take her as their queen. Eventually, she marries the serpent and they are both transformed into a beautiful princess and handsome prince" (Scott \& Scott 2011).

\section{Sabemos que}

os contos de fadas ensinam que através de ligações afetivas com outra pessoa atingimos a suprema segurança emocional e conseguimos as relações mais permanentes que estão ao nosso alcance; e só isto pode dissipar o medo da morte. Se encontrarmos o verdadeiro amor adulto, diz-nos também o conto de fadas, então não precisamos de desejar a vida eterna. Isto é sugerido por outro final; "Eles viveram por muito tempo, felizes e contentes" (Bettelheim 1998, 19).

Esta coletânea de pequenas peças descreve na realidade esta intenção: alcançar um amor maior, um amor eterno. Afastado momentaneamente do seu amor, impossibilitado de o vivenciar numa primeira fase, vemos que, lutando e resistindo, o personagem desta trama o alcança no final.

A proposta musical, composta usando a escala pentatónica e o universo sonoro dos instrumentos de percussão orientais, principalmente os gamelãs, realiza a intenção do compositor em conceber um universo sonoro de características orientais, refletindo a influência e o conhecimento desses mesmos universos de som e arte. Assim, nesta pequena peça com a duração de cerca de 3'28', Ravel mostra a influência das culturas extraeuropeias, não só na temática que escolhe enquanto conto a ilustrar do ponto de vista musical, como nos conteúdos musicais que expressa, propondo-nos uma peça em compasso binário e em tempo de marcha (semínima = 116 M.M.). Rítmica, melódica e metricamente, percebemos essa influência, bem como de todo o imaginário extraeuropeu; a proposta de Tom Scott, fundamental para a sua efetivação.

Ao longo da sua visualização, e à semelhança de todas as demais, a repetição, favorecendo o carácter encantatório do sonoro, é evidente. As variações que introduz, embora subtis, são mais marcantes, pois concretizam-se a nível métrico e textural: $1^{\circ}$ alteração métrica (0'21'); $2^{\circ}$ alteração melódica (0'25", repetindo 0'31"); $3^{\circ}$ alteração elementos figurativos de um universo distante - o oriental (0'39"). Neste sentido, vemos a prática musical na presença de três músicos tocando a flauta transversal, a flauta de pan e o alaúde (ou a Pipa, instrumento tipicamente chinês).

Se num momento inicial o compositor nos introduz num ambiente sonoro mais contido, aquando do aparecimento do tema central da história (0'46"), o carácter musical da pequena peça muda radicalmente. Os elementos musicais surgem agora alocados a figuras humanas, os pagodes e as pagodinas que ajudam ao banho da imperatriz. Nesse sentido, surgem elementos musicais ilustrativos das ações e reações de todos, destacando-se o clímax musical (1'18") onde os pequenos lacaios tocam os gongos com as cabeças, anunciando a desordem e o desatino que a passagem da serpente verde causa a todos, salvo à imperatriz (1'31'), pois que a serpente traz o pânico aos lacaios, mas não à imperatriz. A música transfigura-se num registo grave e escuro, de harmonias mais cerradas e escuras. A serpente passa encantada pela música que todos executam, em especial no saltério (2'30'). Aos 2' e 43", Ravel retoma o motivo inicial anunciando, mais uma vez, a presença de uma forma que denota um plano estrutural tripartido.

\subsection{Les entretiens de la Belle et de la Bête (Os Colóquios da Bela e do Monstro)}

Alguns contos de fadas evoluíram a partir de mitos e lendas, outros foram neles incorporados. Ambos encarnavam a experiência acumulada da sociedade de acordo com a maneira como os homens gostavam de a recordar ou de a transmitir às gerações futuras (Bettelheim 1998). Contudo 
deve-se notar aqui uma limitação especialmente crucial: o verdadeiro sentido, o impacte de um conto de fadas, só podem ser apreciados, o seu encantamento só pode ser sentido se a história for contada na sua forma original (Bettelheim 1998, 30).

Ora, através das propostas de Scott e Ravel, o imaginário contruído enforma-se destas duas realidades. Não nos confrontamos com um texto literário narrado, mas com uma narrativa visual ilustrada por uma proposta sonora em particular. Assim sendo, e de acordo com o exposto por Bettelheim, que dizer de uma segunda, terceira ou quarta leituras e propostas de obra? Que sentido, e que conteúdo, são adquiridos? Que formação psicossocial e moral são conseguidas?

Para além de todas estas questões, surge a obra que, de arte se diz e faz. Assim, a quarta das peças, intitulada Les Entretiens de la Belle et de la Bête, contém também ela uma citação em forma de diálogo entre a Bela e o Monstro.

Quand je pense à votre bon cœur, vous ne me paraissez pas si laid"- " Oh ! Dame oui ! J'ai le cœur bon, mais je suis un monstre."- "il y a bien des hommes qui sont plus monstres que vous" - "si j'avais de l'esprit, je vous ferais un grand compliment pour vous remercier, mais je ne suis qu'une bête. ... La Belle, voulez-vous être ma femme ?" - "Non, la Bête ! ..." "je meurs contente puisque j'ai le plaisir de vous revoir encore une fois". - "Non, ma chère Bête, vous ne mourrez pas : vous vivrez pour devenir mon époux !" ... La Bête avait disparu et elle ne vit plus à ses pieds qu'un prince plus beau que l'Amour qui la remerciait d'avoir fini son enchantement". (Mlle Leprince Beaumont)" (Ravel 1910, 20).

Para a construção da sua pequena peça, Ravel busca mais uma vez um género particular de forma musical que enforma um conteúdo - a valsa, num tempo Très Modéré (Mínima com ponto $=50$ M.M.) (Ravel 1910, 20). A valsa, no seu compasso ternário, realça o primeiro dos tempos do compasso, permitindo, mais uma vez, a repetição, a circularidade, o desenrolar de um universo que se revela, mais uma vez, ondulatório e encantatório. A pequena peça, com uma duração de cerca de 3'42", tem duas partes bem marcadas, concluindo com uma terceira, ilustrativa do amor que, de verdadeiro e real, tudo vence e transforma (3'15').

A história de amor entre uma rapariga muito bela e um rapaz enfeitiçado que se revela um monstro surge nas duas personagens ilustradas de forma distinta; vejamos a mudança de sonoro proposto pelo compositor aquando da chegada do monstro (1'15") (Scott \& Scott 2011). O clímax do diálogo estabelecido na presença dos dois interlocutores surge aos 2' 05", sendo que Bela desaparece para fora de cena, para o terraço. O Monstro não se aquieta e, depois de encontrar a rosa no chão, símbolo da sua paixão (2'20"), a leva a Bela num acelerando e crescendo musical vibrante e marcado (2'42"). A rosa, agora colorida e envolta numa luz, surge como símbolo de uma paixão e de um amor transformador. Transformador é também o beijo (2' 50"). Depois deste, o Monstro se transforma num Belo Príncipe, e a rosa, elemento dessa grande paixão e ardente Amor, se torna elemento central de toda a narrativa e ação.

\subsection{Le jardin féerique (O Jardim Feérico)}

A última das peças, Le jardin féerique,

is a tale of Ravel's own imagination. It brings the work full circle and depicts the awakening of the Sleeping Beauty by a kiss from Prince Charming. They process through the Fairy Godmother's garden and the movement climaxes with fanfares and wedding bells as they all live happily ever after" (Scott \& Scott 2011).

Nesta última peça, Ravel propõe-nos uma peça em compasso também ele ternário num andamento Lento e Grave (semínima = 56 M.M.) (Ravel 1910, 28). Na proposta de Scott, a ação inicia com a mesma luz da primeira das ilustrações, encaminhando o personagem pelo jardim encantado (Scott \& Scott 2011). Atravessando um portal transforma-se a ação (1'06"). O personagem sobe umas escadas em caracol por entre a luxuriante vegetação pintada de branco e negro. Percebemos que a subida se faz até à Bela que se encontra adormecida (1'44"). A luz baloiça sobre Bela (2'10"); o Príncipe a beija, e, a luz, se transforma em várias cores (2'14"); rosa, verde, azul, amarelo, e assim sucessivamente, inundando Bela Adormecida, que acorda com o beijo do seu Príncipe (2'35'), e levantando-se (2'53") se deslocam os dois para uma janela do palácio. Percebemos a transformação de todos, pois até que da noite se faz dia, e se dá o segundo clímax da obra (3'10"). Quando os dois surgem à porta do castelo, os glissandos imperam, ilustrando a felicidade de todos, inclusive de todas as personagens e criaturas que ilustram os cinco pequenos contos infantis. Assim, e no final de toda a obra, surgem todos os personagens humanos e animais (3'31"): a borboleta e o Pequeno Polegar; o cuco, o grilo, a Imperatiz, o mocho, todos se juntam para ilustrar o final feliz, a apoteose de qualquer conto de fadas (Scott \& Scott 2011).

Do ponto de vista formal, a narrativa visual encerra uma forma em arco pois que se projeta para um final feliz e apoteótico, englobando elementos de todos os contos narrados por Perrault através das imagens de Scott e sonoridades de Maurice Ravel.

\section{Considerações finais}

A criança de hoje não cresce na segurança de uma grande família ou de uma comunidade bem integrada. Assim, mais ainda do que no tempo em que foram inventados os contos de fadas, é importante fornecer à criança imagens dos personagens, dos heróis e das heroínas, mais consentâneas com as vivências e existências de hoje (Bettelheim 1998). Mesmo que os conflitos internos sejam os mesmos, as crianças estão hoje muito mais despertas para outros meios de difusão de conhecimento e arte. Aquilo que as 
desperta, bem como à sua atenção, pode efetivamente passar pelo médium em uso. No caso do médium visual, e da narrativa fílmica em particular, percebemos nesta nossa proposta, a confluência da tradição e da modernidade. A tradição mostra-se no corpo de obras sugerido, nos problemas e possibilidades manifestos, no imaginário transmitido e vivido. A modernidade, revela-se no traço, nas formas e cores, projeções e objetos, ideais e ideários propostos. Sabemos ser

importante fornecer à criança modernas imagens de heróis que têm de se lançar no mundo sozinhos e que, apesar de não saberem à partida como é que as coisas se vão resolver, acham lugares seguros no mundo, seguindo para a frente com profunda confiança interior (Bettelheim 1998, 20).

A maior parte das crianças toma conhecimento e contacta com a literatura infantil através de contos de fadas que se encontram quantas vezes infantilizados e simplificados, comprometendo a sua compreensão, formação e moralização. Nestas versões, os seus autores abrandam o seu sentido retirando-lhes qualquer significado mais profundo. Para alguns autores, nomeadamente Bettelheim, versões tais como as dos filmes e espetáculos da TV, em que os contos de fadas se transformam em divertimentos vazios de sentido, são a ignorar (Bettelheim 1998).

\begin{abstract}
Ma Mère l'Oye, da autoria de Maurice Ravel, [...] não pode e não deve ser pensada como uma pura e ingénua manifestação musical, mas como parte ativa e integrante da cultura de uma época. Ravel não utilizou os contos de fadas como algo que ele simplesmente incorporou do ambiente; muito além disso, ele encontrou neles, uma expressão de sua forma de pensar e de suas conceções sobre arte e mundo. As ideias que circulavam sobre o inconsciente, as enigmáticas correspondências entre natureza e mundo celeste divulgadas por Baudelaire e a utilização do mistério e da perfeição estética pregados por Allan Poe, estão, certamente, manifestas em Ma Mère L'Oye. Mas também nela, através de efeitos e cenários sugestivos elaborados numa linguagem rica e em perfeita integração concordantes às ideias tão prezadas pelos poetas simbolistas, se mostra a imaginação e o mundo interior e espiritual do compositor" (Baião 2005, 46).
\end{abstract}

No que concerne a obra musical, Ravel soube ilustrar o ideário dos contos de fada propostos por Perrault, bem como integrar as influências e características técnicas e estilísticas do seu fazer musical. A partir da primeira versão da obra, aquela que se apresentou mais consentânea com o universo e imaginários infantis, Scott propõe a sua proposta fílmica, sem desconsiderar os ritmos e as formas da obra musical. Aceitando os ritmos harmónicos, texturais e formais da obra, o autor expõe os seus conteúdos imagem, ilustrando o universo da história narrada. Acresce o plano formal delineado pela obra no todo e nas partes, que se encontra redita, nos elementos imagem.
No nosso entender, e à semelhança de Bettelheim, os contos de fadas não têm igual, não só como forma de literatura, mas como obras de arte plenamente compreensíveis para a criança, como nenhuma outra forma de arte o é. Tal como a verdadeira arte, o sentido mais profundo do conto de fadas difere de pessoa para pessoa, e difere para a mesma pessoa em momentos diferentes da sua vida". (Bettelheim 1998, 21).

Assim é com toda a forma de arte.

No caso particular da proposta de Scott para a obra Ma Mère l'Oye de Maurice Ravel, entendemos que à proposta musical foi acoplada uma nova proposta que se enforma de maneira eficaz e coerente nos propósitos e objetivos dos contos de fadas. Em outro, a narrativa do conjunto faz-se da narrativa das partes, dando sentido e originalidade ao facto. Percebemos também, que a componente formadora e moralizadora da obra se concretiza no final da obra, contribuindo para a sua realização e eficácia.

\section{Referências bibliográficas}

Baião, D. B. 2005. Ma Mère L'Oye: os (des)limites da interpretação. Dissertação de Mestrado. UFMG: Belo Horizonte.

Bettelheim, B. 1998. Psicanálise dos contos de fadas. Venda Nova: Bertrand Editora.

Lamarque, L. 1992. Encyclopédie de la musique. L Pochothèque. Paris: Librairie Générale Française.

Perrault, Ch. 1994. Contes de Ma Mère l'Oye). Paris: Librio.

Ravel, M. 1910. Ma Mère L'Oye: 5 pièces enfantines pour piano à 4 mains. Paris: A. Durand \& Fils, editeurs.

Robert, Fr. 1963. La musique française au XIXème siècle. Collection: Que sais-je? Paris: Presses Universitaires de France.

Scott, T. \& Scott, J. 2011. Maurice Ravel Mother Goose: Animation by Tom Scott. http://www.scottbrothersduo.com/ ravelmothergoose.htm. Acedido a 12 de março de 2019.

Tranchefort, Fr.-R. 1985. Guide de la musique symphonique. Col. Les indespensables de la musique. Paris: Fayard.

\section{Notas finais}

${ }^{1} \mathrm{O}$ duo é composto pelos irmãos Jonathan Scott e Tom Scott (Scott \& Scott 2011).

${ }^{2}$ Neste sentido, referimos a título de exemplo os romenos George Enescu (1881-1955) e Stan Golestan (1875-1956), o inglês Frederick Delius (1862-1934), o americano Swan Hennessy (1866-1929), o italiano Alfredo Casella (1883-1947), os húngaros Béla Bartók (1881-1945) ou Zoltán Kodály (18821967), os espanhóis Manuel de Falla (1876-1946) ou Isaac Albeniz (1860-1909). Simultaneamente, diversas digressões europeias passam pela cidade sendo que, neste contexto, e a nível musical, a presença de Arnold Schoenberg (1874-1951) e Igor Stravinsky (1882-1971) se destacam.

${ }^{3} \mathrm{~A}$ inspiração em motivos florais e vegetais encontra-se diretamente na chamada Arte Nova, seja ao nível da decoração, do mobiliário, da pintura, escultura, arquitetura, etc.

${ }^{4}$ A criação musical para os espaços públicos ao ar livre traz diversos constrangimentos a quem cria e a quem produz. Por outro lado, e face ao público a que se dirige, pode exigir meios mais numerosos e uma logística maior.

${ }^{5}$ Neste contexto referimos: Habanera (1895); Rapsodie Espagnole (1907); Tzigane (1922-24); L'heure espagnole 
(1907-11) ou Don Quichotte à Dulcinée (1932-33).

${ }^{6} \mathrm{~A}$ discussão alastrou progressivamente a toda a sua produção artística (Lamarque 1992).

$7 \mathrm{Se}$ atendermos à obra que queremos analisar, vislumbramos o mesmo facto: a obra composta inicialmente para piano foi, em seguida, orquestrada pelo compositor, e alvo de uma adaptação para ballet.

8 Através desta obra, Ravel invoca um turbilhão fantasmagórico e caricatural, enunciando os múltiplos aspetos, tanto culturais como artísticos, estruturais e formais, de uma forma musical de dança - a valsa- cuja história se confunde com a da capital de um império moribundo - Viena de Áustria.

${ }^{9} \mathrm{Em}$ exemplo, podemos referir o facto de que o compositor, mais do que utilizar sistemas diferenciados da tonalidade como outros dos seus colegas, prefere utilizar os elementos dessa mesma tonalidade de uma forma inovadora. Assim, sobre uma base rítmica e harmónica tonal, o compositor desenvolve uma melodia diatónica e modal sustentada por uma harmonia cromática. A sobreposição proposta faz com o que compositor possa ser considerado não só um novo clássico, como um novo barroco.

${ }^{10}$ Este facto surge mesmo antes dos exemplos fornecidos, à época, por Igor Stravinsky (Robert 1963).

${ }^{11}$ Em exemplo, a sua obra Boléro (1928), uma obra magistral do ponto de vista dos processos de repetição e variação de um mesmo motivo. Em outro, sobressai a orquestração que desenvolve e a complexificação da textura musical que edifica.

${ }^{12}$ Ravel compôs a obra como uma suíte de 5 peças para piano entre os anos de 1908 e 1910. A sua primeira audição teve lugar em Paris a 20 de abril de 1910. A obra possui uma versão para ser tocada a 4 mãos, uma para orquestra, outra para ballet e ainda aquela que aqui apresentamos.

${ }^{13}$ Veja-se a segunda das peças - Petit Poucet (Pequeno Polegar); a terceira das peças - Laideronnette, Impératrice des pagodes (Laideronnete, Imperatriz dos Pagodes, inspirada no conto "A Serpente Verde" da autoria da Condessa d'Aulnoy), ou a quarta das peças - Les entretiens de la Belle et de la Bête (Os Colóquios da Bela e do Monstro da autoria de Madame Leprince de Beaumont).

${ }^{14} \mathrm{~A}$ primeira audição da obra na sua versão de Ballet teve lugar a 28 de janeiro de 1912, em Paris. A orquestra contempla: 2 flautas e 1 flautim; 2 oboés e 1 corne inglês; 2 clarinetes; 2 fagotes e 1 contrafagote; 2 trompas, tímpanos, triangulo e címbalos, caixa e tam-tam, xilofone, glockenspiel, celesta, harpa e cordas. A obra tem a duração aproximada de 28 minutos.

${ }^{15}$ Contemporâneo de Jean de La Fontaine, Charles Perrault também foi advogado e exerceu algumas atividades como superintendente do Rei Luis XIV de França.

${ }^{16} \mathrm{Em}$ exemplo: La Belle et la Bête de Jean Cocteau.

${ }^{17}$ Dos séculos XVI e XVII, destacam-se as obras de Giambattista Basile e Matteo Bandelo na Itália; Cervantes e Quevedo na Espanha; e na França, Margarida de Navarra, La Fontaine, Charles Perrault, Madame D'Aulnoy e Madame Leprince de Beaumont. (Baião 2005, 47-48).

${ }^{18} \mathrm{Na}$ obra para piano a quatro mãos.

${ }^{19}$ Além do já citado, a versão orquestral contém um prelúdio, a Dança da Roca de Fiar e alguns interlúdios. 